\title{
Cooperação Internacional em Saúde: prioridades e desafios
}

Priscila Almeida ANDRADE ${ }^{1}$

\section{INTRODUÇÃO}

A globalização é um processo resultante do crescimento da rede de interdependência entre os continentes. Caracteriza-se pelas múltiplas relações, interligadas pelo fluxo e influência de pessoas, capital, bens, informações, idéias, conhecimentos, tecnologias e substâncias relevantes no aspecto biológico e ambiental. Nesse cenário, há um movimento de mão dupla no qual a saúde se coloca como uma questão das relações internacionais, assim como a governança global repercute nas políticas nacionais de saúde.

A saúde se insere em uma superestrutura na esfera das relações internacionais, onde se incluem elementos políticos, econômicos e sociais que influenciam as interações entre os países. Para compreender a saúde como uma área da política externa é fundamental analisar as regulações, regras, práticas, recomendações e comportamentos estabelecidos na arena internacional; e a circulação de capital, pessoas, tecnologias, conhecimentos, bens e serviços entre as partes do globo. Esse fluxo possibilita que certas ações no âmbito da saúde se orientem por determinados interesses político-econômicos, podendo aproximar fronteiras e favorecer as negociações diplomáticas, por meio da cooperação internacional. Outro olhar consiste no entendimento das questões da esfera internacional que influenciam o processo saúde-doença e a gestão nacional dos sistemas de saúde.

Desse modo, promover a cooperação internacional em saúde significa também aprender a manejar os problemas e impactos da globalização. O conhecimento sobre o movimento e as agendas dos atores internacionais, como os blocos de integração regional

- Brics e Mercosul, por exemplo - e organizações internacionais (OI), assim como a identificação das capacidades, limitações e interesses dos países desenvolvidos e em desenvolvimento contribuem para a definição de áreas e estratégias para os projetos de cooperação. Para melhor desenvolver esse tema, o presente texto apresenta o argumento em duas partes.

A primeira convida o leitor a refletir sobre o processo de cooperação internacional. Na segunda sessão, é abordada a agenda internacional de saúde e os desafios que precisam ser considerados na gestão do SUS.

1 Mestre em Política Social pela Universidade de Brasília. Professora e pesquisadora da Universidade de Brasília. Contato: priscila@unb.br 


\section{COOPERAÇÃO INTERNACIONAL}

O mundo globalizado caracteriza-se pela interdependência complexa que corresponde à existência de múltiplos canais de ligação entre sociedades, universidade, mercado e governo. Abrangem desde interações informais entre atores públicos e privados até relações intergovernamentais formais. A ausência de hierarquia entre países e entre as questões na agenda internacional é uma característica central da governança global, resultando, entretanto, em pesos e prioridades diferenciadas entre os distintos setores, como economia e saúde.

A política internacional é definida como o conjunto de práticas, regras e princípios que possibilita a relação entre os países. É influenciada, como também impacta no ciclo das políticas públicas nacionais em suas distintas fases2.

Mesmo com a existência de interesses comuns, o Cooperação Internacional em Saúde: prioridades e desafios Tempus Actas de Saúde Coletiva Políticas Públicas de Saúde: textos e contextos comportamento estratégico isolado de cada país é insuficiente para solucionar as demandas da gestão em saúde. Isso gera incentivos para que aceitem limitações em sua capacidade decisória individual em favor de mecanismos coletivos.

Os dilemas e disputas de interesses também podem emergir nesse cenário, impulsionando a cooperação que se faz necessária para minimizar custos sociais e econômicos, reduzir incertezas, potencializar intervenções e compartilhar bens e serviços. Isso significa que a partir de conflitos e de restrição na autonomia no plano nacional é possível gerar cooperação com reciprocidade dos benefícios.

Planejar um projeto de cooperação internacional em saúde demanda conhecer os riscos das externalidades positivas ou negativas; as capacidades e limitações de cada ator; e os interesses em jogo nacionais e globais no âmbito político, econômico e sanitário.

As externalidades negativas correspondem aos efeitos indiretos das deficiências e adversidades de um processo em um determinado local ou população, que podem atingir outras partes do globo, apesar de essas não sofrerem em decorrência das mesmas deficiências ou adversidades. Por outro lado, as externalidades positivas são efeitos que decorrem da ação em um dado local que pode trazer benefícios diretos ou indiretos para outras localidades e coletividades.

A cooperação bilateral ocorre entre dois países e a multilateral entre três ou mais, geralmente intermediada por uma OI. O multilateralismo caracteriza-se pelo estabelecimento de princípios, pela lógica da indivisibilidade e da reciprocidade difusa para nortear a cooperação internacional entre os atores.

O conceito de indivisibilidade indica que os princípios acordados são aplicados a todos os atores envolvidos. A reciprocidade difusa associa a idéia de benefício mútuo entre as partes, não // Tempus, actas de saúde colet, Brasília, 8(2), 97-102, jun, 2014. 
se limitando às trocas. A cooperação internacional demanda uma contrapartida - econômica, técnica, política, científica ou tecnológica - dos atores, os quais, por sua vez, buscam defender ou potencializar seus interesses ao realizar um acordo que se concretiza por projetos de cooperação.

Por outro lado, a assistência internacional, também conhecida como ajuda externa, promove esforços unilaterais de uma parte para gerar um potencial benefício à outra, estabelecendo uma relação entre países doadores e os receptores3.

A partir da negociação entre os países, definem-se a agenda de prioridades das OI. Quando aprovadas suas resoluções e normatizações, legitima-se a expectativa dos atores sobre o comportamento dos países em uma determinada área técnica, gerando uma pressão para sua implementação no âmbito nacional.

Há, portanto, uma influência recíproca entre a agenda sanitária do país e a internacional. Desse modo, é fundamental que a gestão do SUS revise periodicamente suas prioridades de cooperação internacional, fortaleça alianças e esteja representada nos comitês consultivos e deliberativos (boards) e nos fóruns internacionais por gestores da área técnica relacionada.

Essas iniciativas são capazes de conquistar espaços, para que os interesses do país tenham expressão técnico- política nas arenas internacionais.

\section{AGENDA DE SAÚDE GLOBAL: PRIORIDADES E REFLEXÕES}

Atualmente, pesquisadores e gestores da área de cooperação internacional em saúde têm defendido a diferenciação dos termos 'saúde internacional' e 'saúde global'. A saúde internacional era um termo usado com considerável freqüência desde o final do século XIX e referia-se, especialmente, ao controle de epidemias e endemias que ultrapassavam as fronteiras entre nações. Demandavam, assim, intervenções 'inter- nacionais'. Por outro lado, o termo 'saúde global' ganhou força a partir da década de 1990, passando a indicar um conjunto de demandas e necessidades de saúde da população mundial, acima dos interesses de nações em particular.

À saúde global, associam-se também a idéia de uma crescente importância de atores para além das OI intergovernamentais, como a Organização Mundial de Saúde (OMS), incluindo também no cerne da análise a atuação da mídia, das organizações internacionais não governamentais, fundações internacionais e empresas transnacionais4. Logicamente, os termos 'internacional', 'intergovernamental' e 'global' não são mutuamente excludentes e podem ser entendidos como complementares. A concepção de saúde global é fundamental, uma vez que o setor saúde também se insere na ordem mundial, interferindo, mas, ao mesmo tempo, sofrendo os efeitos da globalização5.

No âmbito da saúde, o fenômeno da interdependência complexa é facilmente percebido quando os aspectos sanitários de um determinado local produzem efeitos externos, negativos ou positivos, em outras localidades, independentemente de qualquer ação ou desígnio destas. Caso 
$100 / /$

essas externalidades sejam negativas existe uma probabilidade de ocorrer prejuízos nos aspectos econômicos, políticos e sociais da comunidade internacional6.

Podem ser consideradas ameaças à saúde da população mundial a concentração de conhecimentos

e tecnologias em saúde; a restrição do acesso a medicamentos, equipamentos e vacinas a certos países devido à proteção patentária e à barreira das normatizações técnicas; a focalização do interesse das indústrias por mercados de determinados países, por áreas de fronteira tecnológica - como células-tronco - e por doenças prevalentes nos países desenvolvidos; a bio- -invasão por armas biológicas; e o fluxo de pessoas e animais portadores de certos microrganismos ou enfermidades.

Nessa lógica, a saúde global estabelece um elo de interdependência social, política e econômica entre países.

Frente a esse contexto, na década de 1990, proliferaram, no cenário internacional, atores e iniciativas para fins de cooperação internacional. A OMS, a partir da pactuação dos países, identificou nos anos de 1990 um conjunto de lacunas de intervenção e de pesquisa, formulando a Agenda Inconclusa de Saúde, que define como prioridades: morbi-mortalidade materno-infantil; resistência anti-microbiana (Mycobacterium tuberculosis, o Streptococus peneumoniae, o Plasmodium falciparum); HIV/aids; doenças não-transmissíveis e agravos, com destaque para as cardiopatias, transtornos mentais, neoplasias e doenças respiratórias crônicas; equidade em saúde e eficiência dos sistemas e serviço de saúde. Para responder à Agenda Inconclusa de Saúde, a comunidade internacional gerou a expectativa de que os países em desenvolvimento deveriam priorizar as doenças negligenciadas, como ação estruturante da cooperação internacional. No entanto, a gestão em saúde dos sistemas universais e em países onde a transição epidemiológica é um fenômeno presente, como no caso do Brasil, precisa considerar também os outros agravos e enfermidades que acometem a sua população7.

Para promover a gestão da cooperação internacional em saúde, recomenda-se que os gestores aprofundem as seguintes reflexões em sua prática profissional:

1. Como está estruturada a cooperação internacional no Ministério da Saúde, na perspectiva depromover a negociação do Brasil nos fóruns internacionais e implementar, nacionalmente, as demandas e acordos pactuados?

2. Qual a estimativa de recursos que o SUS tem investido na cooperação internacional?

3. Quais são as áreas estratégicas?

4. Quais são as estratégias adotadas para a definição das políticas e programas do SUS e parceiros do Brasil nos projetos de cooperação bilateral, regional (ex: Brics, Palops, Mercosul) e 
multilateral?

5. Como se realiza a articulação e a gestão dos projetos de cooperação internacional entre as três instâncias do SUS?

6. Qual a relevância e os desafios da gestão em saúde em promover a articulação com os atores responsáveis pela política externa brasileira, na perspectiva de assegurar a priorização da saúde na agenda de negociação internacional do país?

7. Quais as políticas e programas do SUS que são priorizados nos projetos de cooperação internacional?

8. Com quais países os programas do SUS têm priorizado estabelecer cooperação bilateral?

9. Quais áreas tem promovido a cooperação no âmbito dos processos de integração regional, como o Mercosul e Brics?

10. Qual o papel das OI (ex: OMS, Banco Mundial, Fundação Bill e Melinda Gates) na cooperação em saúde com o Brasil?

Essas são algumas questões desafiadoras que a gestão do SUS necessita lidar. A BVS do Núcleo de Estudos sobre Bioética e Diplomacia em Saúde (http:// www.bioeticaediplomacia. org/) apresenta uma interessante literatura técnico-científica sobre a interface entre saúde global e relações internacionais.

\section{CONSIDERAÇÕES FINAIS}

Entender o movimento das organizações internacionais e a pluralidade de iniciativas, a fim de identificar as sinergias, superposições, contradições de agendas e pulverização de recursos é essencial para se gerenciar as atividades de cooperação bilateral ou multilateral.

Diante dos desafios e oportunidades que marcam o cenário global, recomenda-se que a gestão do SUS fortaleça as alianças entre os países em desenvolvimento, como com os membros do Brics e do Mercosul.

Aagenda de prioridades do SUS no âmbito internacional necessita ser dinâmica e sistematicamente revista, abordando históricos desafios como a vigilância em saúde; a assistência na zona de fronteiras; e a implementação do Regulamento Sanitário Internacional.

Por outro lado, despertar também para temas emergentes relacionados à sustentabilidade do SUS, como o desenvolvimento e acesso de tecnologias.

Nessa perspectiva, destaca-se como estratégica a cooperação para o estabelecimento de 
$102 / /$

parcerias público- privadas para o desenvolvimento de tecnologias prioritárias para o SUS e a realização de vigilância e monitoramento tecnológico, considerando as patentes vigentes, as fases de desenvolvimento (pré-clínico e clínico) de tecnologias emergentes e a oferta de serviços tecnológicos no mercado internacional.

Diante da amplitude das questões abordadas, a cooperação internacional em saúde se coloca como uma área prioritária de pesquisa e de ação.

\section{REFERÊNCIAS BIBLIOGRÁFICAS}

1- Keohane, R; Nye, J. Power and interdependence. 3. ed. New York: Longman; 2001. p. 334.

2- Castro, M. De Westphalia a Seattle: a teoria das relações internacionais em transição. Brasília: UnB; 2001. p. 66.

3- Herz, M.; Hoffmann, A. Organizações internacionais: história e práticas. Rio de janeiro: Elsevier; 2004. p. 268.

4- Brown, Th.; Cueto, M.; Fee, E. A transição de saúde pública 'internacional' para 'global' e a Organização Mundial da Saúde. História, Ciências, Saúde - Manguinhos, Rio de Janeiro. 2006; 13 (3): 623-47.

5- Gravel, L.; Lamarche, P. A survey of international health. In: Pan American Health Organization. International health: a north south debate. USA: PAHO/ WHO; 1992. p. 105-112.

6- Hochman, G. A era do saneamento: as bases da política de saúde pública no Brasil. São Paulo: Hucitec/ Anpocs; 1998. p. 261.

7- Almeida-Andrade, P. Análise da Política Nacional de Ciência, Tecnologia e Inovação em Saúde (1990 a 2004): a influência de atores e agendas internacionais. Dissertação (Mestrado em Política Social) - Instituto de Ciências Humanas, Universidade de Brasília, Brasília; 2007. p. 224. 